\title{
İnme Sonrası Erken Dönem Epileptik Nöbet Geçiren Bir Olgunun Kolcaba'nın Konfor Kuramına Göre Değerlendirilmesi
}

\author{
Evaluation of a Patient With Epileptic Seizure Who Returned Early After a Stroke According to \\ the Comfort Theory of Kolcaba
}

Türkan ÇALIŞKAN ${ }^{1}$, Ayfer KARADAKOVAN²

${ }^{1}$ Balıkesir Üniversitesi Sağıı Bilimleri Fakültesi Hemşirelik Bölümü İç Hastalıkları Hemşireliği Anabilim Dalı, Balıkesir,Türkiye

${ }^{2}$ Ege Üniversitesi Hemşirelik Fakültesi İç Hastalıkları Hemşireliği Anabilim Dalı,İzmir,Türkiye

\section{Özet}

Bireyin nörolojik fonksiyonlarının kalıcı ya da geçici kaybıyla sonuçlanan kronik bir hastalık olan inme sonrasında, kayıp yaşanan enstrümental günlük yaşam aktivitelerinin yeniden kazanılmasında hemşirelik bakımının konfor sağlayıcı rolü önemlidir.Bu yazıda, Konfor kuramı çerçevesinde; inme tanısı almış ve epileptik nöbet geçiren 82 yaşındaki erkek bir olgunun, aktivite kısıtlılığı nedeni ile yaşadığı konfor sorunlarına ilişkin hemşirelik yönetimi ele alınmış ve kuramın kullanımına yönelik bir örnek oluşturulması amaçlanmıştır.

Anahtar Kelimeler: İnme, Epilepsi, Konfor, Hemşirelik Kuramı

\begin{abstract}
After stroke, which is a chronic disease that results in permanent or temporary loss of the neurological functions of the individual, the comforting role of nursing care is important in regaining lost instrumental daily life activities. In this article, in the framework of Comfort theory; nursing management of comfort problems experienced due to the strock of a eighty-two-year-old male patient who had a strock diagnosis and had activity restriction and to provide an example of the use of theory.
\end{abstract}

Keywords:Strock, Epilepsy, Comfort,NursingTheory

Yazışma adresi: Türkan ÇALIŞKAN, Balıkesir Üniversitesi Sağlık Bilimleri Fakültesi Hemşirelik Bölümü İç Hastalıkları Hemşireliği Anabilim Dalı, Balıkesir,Türkiye, Tel: 053230780 05, Mail:turkanc@balikesir.edu.tr

ORCID No (Sirasiyla): 0000-0002-7808-2363, 0000-0002-7225-6860

Geliş tarihi: 27.06 .2020

Kabul tarihi: 02.12.2020

DOI: $10.17517 /$ ksutfd. 758967 


\section{GİRIŞ}

İnme bütün dünya ülkeleri için önemli bir morbidite ve mortalite nedenidir (1). Beyin kan akımının çeşitli sebeplere bağlı olarak aniden kesilmesiyle nörolojik kayıplara $(2,3)$ sebep olan inmede işlevler hafif, orta veya ciddi şekilde, kalıcı veya geçici olarak bozulabilir $(4,5)$. Temel kişisel ihtiyaçların çoğunun yardımla karşılayabilecek düzeyde bağımlı hale gelmesiyle sonuçlanabilir $(6,7)$. Bağımlılık bireyin yaşam kalitesinin ve konfor düzeyinin düşmesine yol açabilir.

Konfor hissi bireyin bedenen, zihnen ve ruhsal yönden arzuladığı ya da ihtiyaç hissettiği duyguların ifade şeklidir $(8,9,10)$. Konfor kavramı hemşirelik kuramlarında ele alınan bir kavramdır. Peplau'nun kuramında temel bir gereksinim, Orlando'nun kuramında fiziksel ve mental olarak konforu artıran durum, Roy'un adaptasyon modelinde psikolojik konfor, Watson'un modelinde bakımın sıklıkla bir değişkeni iken Kolcaba konforun rahatlık sağlayıcı yönüne ağırlık vermiştir (11,12). Rahatlık/konfor ihtiyacı insanın yaşam boyunca anlamlı bir ihtiyacı olmuş dolayısıyla hemşireliğin doğasında çok öncelerden beri var olan bir kavram olarak yerini almıştır (13). Konfor kuramına göre hemşire; hasta ve aile üyelerinin rahatlık ihtiyaçlarını belirler ve bu ihtiyaçları karşılamak için girişimlerini tasarlar ve uygular.

Kolcaba, konforu bireyin gereksinimleri ile ilgili yardım, huzuru sağlama ve sorunların üstesinden gelebilme durumu olarak tanımlamaktadır (14). Hastaların konfora olan gereksinimini demans ünitesinde çalıştı̆̆ 1 yıllarda fark eden Kolcaba (12), kavram analizi çalışmaları sonucunda holistik konfor kuramını iki boyutta açıklamıştır (Tablo 1). Taksonomik yapıdaki konfor kuramını sütunlar ve satırlar olarak ifade etmiştir $(8,9,10,12)$.

Konfor kuramında konfor düzeyi ferahlama, rahatlama ve üstünlük olarak üç aşamadan oluşmaktadır. Ferahlama; gereksinimleri karşılanan bireyin sıkıntıdan kurtulması ile hissettiğidir. Herhangi bir ihtiyacın karşılanması sonucu yaşanır. Rahatlama; sakin ve huzurlu olma durumudur. Hastanın iyileşmesi için gerekli konfor ve onun iyileşmeye olan katkısı ile pozitif ilişkili, kalıcı bir durumdur. Üstünlük; bireyin kendi gücünü arttırması ile sorunların üstesinden gelebilmesi durumudur. Bu üç gereksinim alanında konforu karşılanmayan birey eksiklik hisseder. Gereksinimleri giderildiğinde ise eksiklik ortadan kalkar $(15,16,17)$
Kuramda konforun boyutları ise fiziksel, sosyokültürel, psikospiritüel ve çevresel konfor gereksinimleri olarak dört aşamada tanımlanmıştır. Fiziksel boyutta konfor gereksinimleri, homeostatik mekanizma, bağışıklık durumu, bedensel algıları (dinlenme, gevşeme, hastalığa karşı yanıtlar, beslenme, hidrasyon vb.) kapsamaktadır (18). Sosyokültürel boyuttaki konfor gereksinimleri, sosyokültürel rahatlık aile ve diğer sosyal kurumlarla etkileşimleri ve kişiler arası ilişkileri kapsar. Sosyal ve kişiler arası ilişkileri düzenleyen gelenekler, kurallar ve dinsel, yasal özellikler bu kapsamda yer almaktadır $(8,11)$. Psikospiritüel boyutta konfor gereksinimlerinde, kişinin akılsal, ruhsal ve manevi durumunu (kendine güven, öz saygı, cinsellik, yaşamın anlamı) ifade edilmektedir $(10,16,17)$. Bireyin çevresindeki ışık, ses, koku, renk, sıcaklık, mobilya, manzara gibi fiziksel faktörlerin yanında, bu faktörlerin insan üzerindeki etkileri çevresel konfor gereksinimlerini kapsamaktadır $(8,11,17)$.

Kolcaba, konfor gereksinimlerinin belirlenmesi ve hemşire tarafından yapılan uygulamalardan sonra karşılanan gereksinimlerin hasta konforuna etkisinin değerlendirilmesi için Genel Konfor Ölçeğini (GKÖ) geliştirmiştir. Madde sayısı 48 ve dörtlü likert tipte olan ölçeğin alt boyutları; ferahlama (16 madde), rahatlama (17 madde), üstünlük (15 madde) ten oluşmaktadır. Pozitif ve negatif ifadelerin olduğu ölçekte düşük konfor (1p) (kesinlikle katılmıyorum), yüksek konfor (4p) (kesinlikle katılıyorum) şeklinde ifade edilmektedir. Negatif maddelerde ise bu puanlama ters kodlanmaktadir. Ölçeğin değerlendirilmesi sonucunda elde edilen toplam puan ölçek maddelerinin sayısına bölünerek ortalama değer saptanmaktadır. Ölçeğin iç tutarlılık katsayısı 0,88 olarak belirlenmiştir. Türkiye’de geçerlilik ve güvenirliliği Kuğuoğlu ve Karabacak tarafından 2004 yılında yapılmıştır ve iç tutarlılık katsayısı 0,85 olarak bulunmuştur (19).

Konfor kuramını pratikte uygulamak için öncelikle kuramin taksonomik yapısını kullanarak bireyin konfor gereksinimlerini tanımlamak gerekmektedir (12). Karşılanamayan konfor gereksinimlerine yönelik toplanan veriler ile hastanın konfor düzeyini yükseltmek hemşirelik hedefidir (9). Ancak konforu yükseltme hedefli girişimlere ulaşılıp ulaşılmadığını belirlemek için hastanın bakım öncesi ve sonrası konfor düzeyi GKÖ ile ölçülerek belirlenmelidir (12). Beklenen konfor düzeyinde artış sonucuna göre yeni planlamalar yapılmalıdır (9).

\section{Tablo 1. Konforun taksonomik yapısı}

\begin{tabular}{|l|l|l|l|}
\hline Konfor & Ferahlama & & \\
\hline Boyutları & & & \\
\hline Fiziksel & & & \\
\hline Psikospiritünlük & & \\
\hline Çevresel & & & \\
\hline Sosyokültürel & & \\
\hline
\end{tabular}




\section{OLGU SUNUMU}

Bilgilendirilmiş onamı alınarak görüşmenin başlatıldığ 82 yaşındaki erkek olgu, $1,76 \mathrm{~cm}$ boyunda ve 82 kilodur. Emekli, evli ve üç çocuğu olan bay N.K.'nin sosyal güvencesi mevcuttur. Olgunun geçmiş sağlık öyküsünde beş yıldır antihipertansif(Dilatrend 1x1) ilaç kullandığı saptandı. Geçirilmiş ameliyat öyküsü bulunmayan hastamızın son bir yıldır prostat şikayetinin olduğu öğrenildi.

Olgumuzda alkol, sigara kullanım alışkanlığı ve herhangi bir durum ya da ilaca karşı alerji öyküsü bulunmamaktadır. Soy geçmişine ait özellik tanımlamamaktadır. Son birkaç aydır var olan prostat bulgularına güçsüzlük ve ayağı üzerine basamama şikâyetleri de eklendiğinden 112 aracılığıyla acil servise başvuran olgumuzun yapılan tetkiklerden sonra dördüncü ventrikül odaklı plaklara bağlı dolaşım bozukluğu olduğu saptanmış, tedavisi düzenlenerek (Depakin 1x1; Dilatrend 1x1; Plavix 1x1) taburcu edilmiş. Taburculuğu izleyen ilk 24 saat içinde jeneralize tip nöbet öyküsü ve paraparezi tablosuyla yeniden 112 aracılığıyla acil servise başvuru yapan hastamız ilk acil servis başvurusundaki tetkiklerinin tekrarı ve 24 saatlik acil servis takibinin ardından taburcu edilmiştir. Olgumuzun kızından alınan öyküye göre evinde geçirdiği bir haftalık süre içinde zaman zaman absans tipte nöbetler geçirmekteymiş. Yeniden jeneralize tipte geçirdiği nöbet nedeniyle tekrar 112 aracılığıla acil servise başvuru yapan hastamızın tedavisini düzenleme ve takip amacıyla nöroloji servisine yatışı yapılmıştır.

Servise kabulünde oral alımı sınırlı, uykuya meyilli ve yutkunma problemi mevcut olan N.K boşaltım ihtiyacı için kalıcı kateter kullanmaktadır. N.K’nin refakatindeki kızı ile yapılan görüşmede epileptik nöbet geçirme ve nöbet tekrarı konusunda endişeli oldukları, uykuya meyli ve aspirasyon riski nedeniyle ilaç, besin ve sıvı alımını yönetemedikleri için çaresizlik hissettikleri, hastamızın ise foley kateterden rahatsız olduğu, hareketlerine gelen sınırlılık, bağımsız hareket edememe nedeniyle huzursuz olduğu saptanmıştır.

\section{TARTIŞMA}

Olgumuzun yapılacak girişimler öncesi genel konfor düzeyini belirlemek için GKÖ kullanıldı ve ortalama puanı 2,29 olarak belirlendi. Sonuç olarak değerlendirildiğinde N.K inme ve inmeye bağlı gelişen disfaji odaklı sıvı alımı yetersizliğinden kaynaklanan erken dönem epileptik ataklar nedeniyle konforunun düşük olduğu saptandı. İnmenin yaşamına getirdiği bağımlılığa bağlı uyum problemi ve anksiyete yaşadığ görüldü. N.K’nin ve ailesinin inme nedeniyle yaşamlarındaki ani değişikliğe bağlı bozulan yaşam kalitelerine yönelik konfor kuramının taksonomik yapısına göre hemşirelik tanıları ve girişimleri belirlendi (Tablo 2).

\section{Fiziksel Boyut:}

İnmeli hastaların yaklaşık yarısında disfaji görülmektedir $(20,21)$. Sıklıkla sıvı ve yumuşak gidaları yutma sırasında yaşanan bir sorundur (22) Aspirasyon pnömonisi, dehidratas- yon ve malnütrisyon riskinin artmasına prognozun kötüleşmesine neden olması nedeniyle önemlidir. Sıklıkla inmeden sonraki birkaç hafta içerisinde iyileşir ancak bazı hastalarda trakeostomi yapılması da gerekebilir (20). İnme sonrası erken dönemde görülen epileptik nöbetlerde (23) beslenme ve sıvı alımı yetersizliği tetikleyici bir faktördür (24). Disfaji sonucu gelişen sıvı alımı yetersizliğinin tetiklediği erken dönem epileptik nöbetler ve tekrarlayan epileptik nöbetlerin sonrasında görülen postiktal döneme bağlı uykuya meylin artması beden gereksinimden az besin ve sıvı alımı olgumuzun fiziksel konforunu olumsuz yönde etkilemiştir. Sıvı gıda alımında yutma güçlüğü yaşayan N. K' ya parenteral yolla sıvı desteği verildi. Bakım vericiler ile de görüşerek besleme sırasında yatak içinde tam oturtulması, aspirasyonu önlemek için bu pozisyonun yemekten sonra yarım saat daha korunması, özellikle sıvı verilirken pipet kullanmamaları, çiğneme ve yutkunma için yeterince beklemeleri, yuttuğundan emin olmadan yeni yudum vermemeleri yönünden bilgi paylaşımı yapıldı. Disfaji problemi henüz çözümlenmemekle birlikte aspirasyon pnömonisi gibi fiziksel konforunu bozacak yeni bir problem yaşanmadı. Günlük sıvı alımı ağırlıklı olarak parenteral yolla karşılanan N.K. yakınlarının desteğiyle oral olarak 1000 cc'ye yakın sıvı gıda tüketmeye başladı.

Yatağa bağımlılık, inaktif yaşam, yetersiz beslenme, depresyon, nörojenik durum, kognitif bozukluklar, nedeniyle konstipasyon inmeli hastalarda sık yaşanan bir problemdir $(21,22)$. Klopidogrel, iskemik inmede sekonder korumaya yönelik tedavi seçeneklerinden biridir. Akut dönemden başlayarak yaygın olarak kullanılan sekonder korumaya yönelik ilaçların etkisini inceleyen çalışmalar inme tekrarının önemli ölçüde engellendiği bazı tedavi kombinasyonlarında hemoraji olduğu yönündedir (25). Antikoagülan tedaviye bağlı hemorajik inme görülmese bile basit bir travma hastada ekimoz ya da hematoma sebep olabilir. Olgumuzun inmeye bağlı aktivite kısıtlılığı, uykuya meyil nedeniyle bağırsak boşaltımında değişiklik ve uygulanan antikoagülan tedaviye bağlı travma ve kanama riski olması da fiziksel konforunu etkilemiştir. İnmenin erken döneminde sıvı alımını artırma, diyetin posa miktarını arttırma, dışkı yumuşatıcıları, laksatifler ve enema ile konstipasyon kontrol altına alınabilir (2). Bakım vericileri sıvı alımında rahat olmayan N.K.ye yarı katı, püre kıvamı meyve ve sabahları zeytinyağı içme, yatak içi hareketliliği arttırmaya çalışma gibi teknikleri kullandıklarını ifade etmiştir. Olgumuza yatışının ikinci gününde defekasyon ihtiyacı için yatak yanına komod getirilmiş ve defekasyona çıkmıştır. Olası kanama riskini önlemek için invaziv girişimler daha az sayıda ve planlı yapılmış, travmaya sebep olabilecek durumlardan korunmuş, olası kanamalar için peteşi, hematom, ekimoz, hematüri, hematemez, melena, mental durumda değişiklikler gibi iç ve dış kanama belirti yönünden takip edilmiş, yaşam bulguları, laboratuvar bulguları (trombosit sayısı, Htc., Hb., PT, aPTT) takip edilmiştir. Taburculuk sonrasında da olası kanamalara karşı yapabilecekleri konusunda yakınları bilgilendirilen olgumuzda kanama gibi konfor bozucu bir durum yaşanmamıştır. 


\section{Tablo 2. Konfor Kuramı’nın taksonomik yapısına göre inmeli bireyin hemşirelik bakımı}

\begin{tabular}{|c|c|c|c|}
\hline \multicolumn{2}{|l|}{ Konfor } & \multicolumn{2}{|l|}{ Düzeyleri } \\
\hline \multicolumn{4}{|l|}{ Fiziksel } \\
\hline Oral alımında yetersizlik & $\begin{array}{l}\text { Disfajisi olan hastanın } \\
\text { beslenmesinde dikkat } \\
\text { edilmesi gerekenler ile } \\
\text { ilgili hasta yakınlarının } \\
\text { bilgilendirilmesi } \\
\text { Parenteral yolla beslenmenin } \\
\text { sağlanması }\end{array}$ & $\begin{array}{l}\text { Tedavi düzeni sağlanıncaya } \\
\text { kadar ihtiyacı olan besin } \\
\text { ve ilaçların parenteral yolla } \\
\text { verileceğinin açıklanarak } \\
\text { hasta yakınlarının } \\
\text { rahatlamalarının sağlanması }\end{array}$ & $\begin{array}{l}\text { Uyanık olduğu dönemlerde } \\
\text { besin ilaç ve sıvı alımının } \\
\text { sağlanması, damar yoluyla } \\
\text { desteklenmesi }\end{array}$ \\
\hline Uykuya meylin artması & $\begin{array}{l}\text { Epileptik nöbetler ve evreleri } \\
\text { ile ilgili bilgilendirme } \\
\text { yapılması }\end{array}$ & $\begin{array}{l}\text { Epileptik nöbet sonrası } \\
\text { uykuya meylin doğal bir } \\
\text { süreç olduğunun açıklanarak } \\
\text { hasta yakınlarının } \\
\text { rahatlamalarının sağlanması }\end{array}$ & $\begin{array}{l}\text { Parenteral yolla besin ve sıvı } \\
\text { alımıyla sürecin yönetiminin } \\
\text { sağlanması }\end{array}$ \\
\hline $\begin{array}{l}\text { İnmeye bağlı; bağırsak } \\
\text { boşaltımında değişiklik }\end{array}$ & $\begin{array}{l}\text { İnaktiviteye bağlı bağırsak } \\
\text { boşaltımındaki değişime } \\
\text { yönelik bilgi eksikliğini } \\
\text { giderme ve konstipasyonu } \\
\text { giderici besin alımı listesi } \\
\text { oluşturma }\end{array}$ & $\begin{array}{l}\text { Önerilen besin alımı listesi } \\
\text { ve yatak içi hareketlilik ile } \\
\text { bağırsak alışkanlıklarına } \\
\text { ilişkin bilgi eksikliğinin } \\
\text { giderilerek hastanın } \\
\text { rahatlatılması }\end{array}$ & $\begin{array}{l}\text { Hareketlilik ve listeye uygun } \\
\text { beslenme }\end{array}$ \\
\hline $\begin{array}{l}\text { Antikoagülan tedaviye } \\
\text { kaynaklı kanama riski }\end{array}$ & $\begin{array}{l}\text { Kanama bulgularının takip } \\
\text { edilmesi }\end{array}$ & $\begin{array}{l}\text { Kanama riski yaratabilecek } \\
\text { durumların önlenerek } \\
\text { hastanın rahatlatılması }\end{array}$ & Kanamanın önlenmesi \\
\hline $\begin{array}{l}\text { Psikospiritüel } \\
\text { Aile üyelerinin yutma } \\
\text { güçlüğü ve epileptik } \\
\text { nöbetlere ilişkin endişeleri }\end{array}$ & $\begin{array}{l}\text { Aile üyelerinin endişelerini } \\
\text { ifade etmesinin sağlanması } \\
\text { Endişelerine yönelik inme } \\
\text { komplikasyonları ile ilgili } \\
\text { bilgilendirme yapılması }\end{array}$ & $\begin{array}{l}\text { Endişelerinin giderilerek } \\
\text { rahatlatılmalarının } \\
\text { sağlanması }\end{array}$ & $\begin{array}{l}\text { Endişenin yarattığı anksiyete } \\
\text { ile baş etmenin sağlanması }\end{array}$ \\
\hline $\begin{array}{l}\text { Çevresel } \\
\text { İnmeye bağl1 konforda } \\
\text { bozulma }\end{array}$ & $\begin{array}{l}\text { Girişimlerin konforu en } \\
\text { az etkileyecek şekilde } \\
\text { uygulanması }\end{array}$ & $\begin{array}{l}\text { Girişimlerin günlük yaşam } \\
\text { aktivitelerini etkilemeyecek } \\
\text { şekilde uygulanması }\end{array}$ & $\begin{array}{l}\text { Günlük yaşam aktivitelerinin } \\
\text { hasta tarafından devam } \\
\text { ettirilmesinin sağlanması }\end{array}$ \\
\hline $\begin{array}{l}\text { İnvaziv girişimlere, kalıcı } \\
\text { katatere bağlı enfeksiyon riski }\end{array}$ & $\begin{array}{l}\text { Tüm girişim ve bakımlarda } \\
\text { asepsi kurallarına uygun } \\
\text { davranılması } \\
\text { Enfeksiyon belirti ve } \\
\text { bulgularının takip edilmesi } \\
\text { Hasta ve yakınlarına } \\
\text { Enfeksiyonun önlenmesi ile } \\
\text { ilgili bilgi verilmesi }\end{array}$ & $\begin{array}{l}\text { Enfeksiyon önlenerek } \\
\text { hastanın rahatının } \\
\text { sağlanması }\end{array}$ & $\begin{array}{l}\text { Hasta ve yakınlarının } \\
\text { Enfeksiyonun önlenmesi ile } \\
\text { ilgili bilgi sahibi olması }\end{array}$ \\
\hline İnmeye bağlı düşme riski & $\begin{array}{l}\text { Düşmeyi önleyecek şekilde } \\
\text { çevre düzenlenmesi } \\
\text { yapılması, düşme konusunda } \\
\text { hasta ve yakınlarının } \\
\text { bilgilendirilmesi }\end{array}$ & $\begin{array}{l}\text { Düşmenin önlenerek } \\
\text { konforun devam ettirilmesi }\end{array}$ & $\begin{array}{l}\text { Düşmenin yaralanmaların } \\
\text { önlenerek vücut } \\
\text { bütünlüğünün devamlılığının } \\
\text { sağlanması }\end{array}$ \\
\hline
\end{tabular}




\section{Psikospirituiel Boyut:}

İnme sadece hastanın değil ailelerinin ve bakıcılarının yaşam kalitelerini de olumsuz yönde etkiler (3). Hastalar sıklıkla geçmiş yaşamlarına tekrar dönüp dönemeyecekleri endişesinden kaynaklanan anksiyete ve depresyon yaşayabilirler $(7,24)$. Aile üyeleri epileptik nöbetlerle gelen uykuya meyil ve disfajiye bağlı aspirasyon riski nedeniyle ilaç, besin ve sıvı alımını yönetemedikleri, devam eden bu döngünün epileptik nöbetlerin tekrarına dönüştüğü için çaresizlik hissettiklerini ifade etmişlerdir. Öncelikle aile üyelerinin endişelerini ifade etmelerini sağlayıcı yaklaşım planlandı. İnme sonrası erken ya da geç dönemde epileptik nöbetlerin görülmesinin beklenen bir durum olduğu söylendi. Epileptik nöbetler için tedavi düzeni sağlanıncaya kadar ihtiyacı olan besin ve ilaçların parenteral yolla verileceği, epileptik nöbet sonrası uykuya meylin doğal bir süreç olduğu, erken dönemde görülen nöbetlerin olgumuzda da olduğu gibi yutma güçlüğü kaynaklı elektrolit veya asit baz dengesizliğine bağlı olduğu, antiepileptik ilaç tedavisine cevap verdiğinde uykuya meylin de düzene gireceği, yine de nöbet başladığında tipi, süresi, özellikleri yönünden hastamızı dikkatli gözlemelerini ve hekimi bilgilendirmelerinin tedavi düzeni ve seyrinde etkili olduğu, nöbet geçirdiği sırada hava yolu açıklı̆̆ının sürdürücü önlemleri almaları, nöbet sırasında hastanın başını travmalardan korumaları, antiepileptik ilaçların her gün aynı saate alınmasını, doktor bilgisi olmadan ilaç dozu atlama ya da kesme gibi ezber davranışın nöbet kontrolünü bozacağını ve hastanın hayati tehlikesini arttırabileceği açıklanarak hasta yakınlarının rahatlamaları dolayısıyla psikospiritüel konforları sağlanmıştır.

\section{Çevresel Boyut:}

İnme tüm vücudu etkiler, sıklıkla paralizi, motor kontrol kayıp, duyusal, görsel, bilişsel bozukluklar farklı derecelerde yeti yitimine, uzun süreli bakıma ihtiyacı arttırmaktadır $(4,26,27)$. Bireyin günlük yaşam aktivitelerini bağımsız olarak gerçekleştirmede zorlandığ 127,28$)$ bu süreç konfor alg1sını da olumsuz etkilemektedir. Olgumuz için aktivite kısıtlılığı, güçsüzlük ve yorgunluk nedeniyle istendik sınırlarda aktivite sağlayıcı girişimler planlandı, yatak istirahatine devam edildi, tolere edeceği günlük yaşam aktivitelerini yapması konusunda teşvik edildi, gerektiğinde öz bakım aktiviteleri sırasinda desteklendi.

İnme sonrası özellikle, ekstremitelerde gelişen güç kaybı, kas tonüsündeki değişiklikler, duyu kayıpları, koordinasyon ve denge kaybı düşme riskini arttırmaktadır $(22,26)$.Olgumuzun düşme yönünde öyküsü olmamakla birlikte tanısı ve yaşı nedeniyle riskli grupta olduğu için yakınlarına N.K.nin yalnız bırakılmaması, ihtiyacı olduğunda ulaşabileceği ses çıkaran zil, düdük gibi bir aracın yakınına konulması, ortamın yeterli aydınlatılması ve yatak kenarlıklarının çekilmesi ile düşmeye karşı güvenli bir ortam sağlamıştır.

İnme sonrasinda hastaların yarıdan fazlasında detrusör kası aşırı aktivitesinin sonucu orta veya ağır şiddette üriner ve fekal inkontinans gelişir. İnmenin ilk aşamalarındaki tab- lo zaman içinde yavaş yavaş normale döner. Düzelmemesi kötü prognoz ile ilişkilidir (21). Olgumuzun inme öncesinde başlayan prostat şikayeti inkontinans tablosunun normale dönme sürecini olumsuz yönde etkilemiştir. Foley sondanın uzun süreli kalmasına bağlı gelişebilecek üriner enfeksiyondan korumak için prezervatif sonda takılmış ve mesane eğitim programına da başlanmıştır. N.K'.nin genel tablosu nedeniyle oral sıvı alımı istenen düzeyin altında olduğundan ilerleyen zamanlarda tablo düzeldiğinde sıvı alımında gündüz saatlerini tercih etmeleri, düzenli saat aralığ 1 ile sürgü verme ve hasta bezi kullanma önerileriyle kontinans durumunu yönetmesi ve dolayısıyla çevresel konforunu bozabilecek durumlar kontrol altına alınmaya çalışılmıştır.

\section{Sosyokültürel Boyut:}

GYA'larındaki bağımsızlık taburculuğun belirlenmesinde önemlidir (29). İnme sonrası yaşanan yeti yitimi hastaların hem günlük yaşam aktivitelerindeki öncelik sırasını hem de bunları karşılamadaki bağımsızlıklarını etkiler. Bu durum bireyleri bağımsızlıktan, az ya da çok bağımlı duruma getirmektedir (28).

Anksiyete belirsiz ya da tanımlanamayan bir tehdide karşı bireyin endişe, huzursuzluk hissetme durumudur. İnme sonrası dönemde hastalar sıklıkla geçmiş yaşamlarına tekrar dönüp dönemeyecekleri endişesinden kaynaklanan anksiyete ve depresyon yaşayabilirler. Ağlama veya gülme gibi duygusal tepkilerini kontrol edemeyip sosyal izolasyon yaşayabilirler $(7,24)$. Hastamız inmeye bağlı beden imajında değişim ve tekrar yürüyememek, dışarıya çıkamamak, camiye gidememekten korktuğunu ifade etmektedir. Bireyin anksiyetesini tanımlayabilmesi ulaşılması beklenen ilk hedeftir. Zaman geçtikçe duygusal tepkilerin sıklık ve şiddetinin azalacağını, duygusal tepkiler ileri düzeye ulaştı̆̆ında profesyonel yardım alabilecekleri, hekim istemiyle antidepresan kullanabilecekleri, dikkatini başka yöne çeken aktivitelere yönlendirme gibi etkili baş etme yöntemlerini kullanarak rahatlaması, tolere edebildiği günlük yaşam aktivitelerini bağımsız olarak yerine getirebilmesi önerilerek sosyal konfor düzeyinin artırılması hedeflenmiş ancak olgumuz inmenin erken döneminde olduğu için sonuçları gözlemlenememiştir.

Uygulanan hemşirelik girişimleri sonrasında N.K.nin konfor düzeyinde değişiklik olup olmadığını saptamak için GKÖ tekrar uygulanmıştır. Uygulama sonrası ölçek puan ortalaması 3,04 olarak belirlenmiş ve konfor düzeyinin arttığı kanıtlanmıştır.

Sonuç olarak Kolcaba’nın "Konfor Kuramı” çerçevesinde olgunun bakım süreci; fiziksel, çevresel, sosyokültürel ve psikospiritüel boyutta ele alınarak problemlere yönelik hemşirelik tanıları belirlenmiş ve gerekli girişimler yapılarak holistik olarak konforu sağlanmıştır. Konfor kuramı, temeli bakım olan hemşirelik mesleğine farklı bir bakış açısı kazandırmıştır. Kuram ile inme tanısı alan bireylere sistematik olarak hemşirelik süreci uygulanabileceği, hemşirelik bakımının ana amaçlarından biri olan rahatlık ve konforun sağlanarak yaşam kalitesinin artırabileceği görülmüştür. 


\section{Çıkar çatışması ve finansman beyanı}

$\mathrm{Bu}$ çalışmada çıkar çatışması yoktur ve finansman desteği alınmamıştır.

\section{Araştırma Katkı Oranı Beyanı Özeti}

Yazarlar, yazıya eşit katkıda bulunduklarını beyan ederler.

\section{KAYNAKLAR}

1. Feigin VL, Forouzanfar MH, Krishnamurthi R,Mensah AG, Connor M, Derrick AB, et al. Global andRegionalBurden of Stroke During 1990-2010: FindingsFromthe Global Burden of DiseaseStudy 2010. Lancet (London, England) 2014;383:245-55.

2. Akın S, Durna Z. İnme ve Bakim, Turkiye Klinikleri J InternMedNurs-Special Topics 2016;2(2):10-26.

3. Clare CS. Role of the Nurse in Stroke Rehabilitation. Nursing Standard. Neurology / CPD Evidence\&Practice 2018;33(7):59-66.

4. Karadakovan A. Sinir Sistemi Hastalıkları. Ayfer Karadakovan, Fatma Eti Aslan. Dahili ve Cerrahi Hastalıklarda Bakım. Geliştirilmiş 2. Baskı. Adana: Adana Nobel Kitabevi, 2011; 1204-12.

5. Tülek Z. Sinir Sistemi Hastalıkları ve Hemşirelik Bakımı: İnme. Nuray Enç. İç Hastalıkları Hemşireliği. İstanbul Üniversitesi Florence Nightingale Hemşirelik Fakültesi. İstanbul, 50. Yıl Yayınları, Nobel Tip Kitabevi, 2014;293-9.

6. Schure LM, Van den Heuvel ETP, Stewart RE, Sanderman R, de Witte LP, Meyboom-de Jong B. Beyond Stroke: Descriptionand Evaluation of an Effective Intervention to Support Family Caregivers of Stroke Patients. Patient Education and Counseling 2006; 62(1):46-55.

7. Gençer AG, Hocaoğlu Ç. İnme Sonrası Nöropsikiyatrik Durumlar, Psikiyatride Güncel Yaklaşımlar 2019;11(4):419-37.

8. Karabacak Ü, Acaroğlu R. Theory of Comfort. Maltepe Üniversitesi Bilim ve Sanat Dergisi 2011;4(1):197-202.

9. Çınar Yücel Ş. Kolcabảnın Konfor Kuramı. Ege Üniversitesi Hemşirelik Yüksek Okulu Dergisi 2011;27(2): 79-88.

10. Terzi B, Kaya N. Konfor Kuramı ve Analizi. Anadolu Hemşirelik ve Sağllk Bilimleri Dergisi 2017;20(1):67-74.

11. Zengin N. Konfor Kuramı ve Yoğun Bakım Ünitesinin Hasta Konforuna Etkisi. Yoğun Bakım Hemşireliği Dergisi 2010;14(2):61-6.

12. Orak ŞN. Konfor Kuramı. Ayşe Ferda Ocakçı, Şule Ecevit Aplar. Hemşirelikte Kavram, Kuram ve Model Örnekleri, 1. Baskı, İstanbul, İstanbul Tip Kitabevi, 2013:39-57.
13. Erdemir F, Çırlak A. Rahatlık Kavramı ve Hemşirelikte Kullanım1. DEUHYO ED, 2013;6(4):224-30.

14. Kolcaba KY. A Theory of Holistic Comfort for Nursing. J Adv Nurs. 1994;19(6):1178-84.

15. Kolcaba K, Wilson L. ComfortCare: a Framework for Perianesthesia Nursing. J PerianesthNurs. 2002;17(2):102-11.

16. Kolcaba K. Comfort theory and practice: a vision for holistic health care and research. New York: Springer Publishing Co. 2003:58.

17. Yücel Ş, Ergin E. Yaşlılıkta Konfor. STED 2020;29 (1):69-75.

18. Wilson L, Kolcaba K. Practical Application of Comfort Theory in the Perianesthesia Setting. J Perianesth Nurs. 2004;19(3):164-73.

19. Kuğuoğlu S, Karabacak Ü. Genel Konfor Ölçeğinin Türkçe'ye Uyarlanması, İ.Ü.F.N. Hem. Dergisi 2014;16(61):16-23.

20. Memiş S, Tülek Z. İnmeli Hastalarda Görülen Konuşma Bozukluklarında Hemşirenin Rolü, C.Ü. Hemşirelik Yüksek Okulu Dergisi 2004;8(1):53-61.

21. Eyigör S. İnmeli Hastada Rehabilitasyon Prensipleri. Türk Fiz Tip Rehab Derg. 2007;53 (Özel Say1 1):19-25.

22. Boyraz S. İnmede Akut Dönem Bakımı ve Komplikasyonların Önlenmesi, Türkiye Klinikleri J Intern Med Nurs-Special Topics 2015;1(1):13-21.

23. Ryvlin P, Montavont A, Nighoghossian N. Optimizing therapy of seizures in stroke patients. Neurology 2006;67(12 suppl 4):53-9.

24. Bakar M, Özdağ MF, Melek İ, Uludüz D, Tekgöl Uzuner G, Armağan O, ve ark. İnme Sonrası: Türk Beyin Damar Hastalıkları Derneği İnme Tanı Ve Tedavi Kılavuzu - 2015. Türk Beyin Damar Hastalıkları Dergisi 2015;21(3):169-79.

25. İnce B. İskemik İnmede İkili Antiagregan Tedavi. Türk Beyin Damar Hastalıkları Dergisi 2019;25(2):86-93.

26. Alankaya N. İnme Sonrası Yeti Yitimi Rehabilitasyonu. Yoğun Bakım Hemşireliği Dergisi 2019;23(3):195-201.

27. Langhorne P, Bernhardt J, Kwakkel G. Stroke Rehabilitation. The Lancet 2011; 377(9778):1693-702.

28. Koç A. Rehabilitation Nursing: Applications for Rehabilitation Nursing. International Journal of Caring Sciences2012;5(2):80-6.

29. Duncan PW, Zorowitz R, Bates B, Choi JY, Glasberg JJ, Graham GD, et al. Management of Adult Stroke Rehabilitation Care: a Clinical Practice Guideline. Stroke 2005;36(9):100-43. 